\title{
Fe-Gd-Sb (Iron-Gadolinium-Antimony)
}

\section{Raghavan}

Recently, [2008Liu] determined an isothermal section at $500{ }^{\circ} \mathrm{C}$ for this ternary system, which depicts no ternary phases.

\section{Binary Systems}

The Fe-Gd phase diagram [1998Zha] depicts the following intermediate compounds: $\beta \mathrm{Fe}_{17} \mathrm{Gd}_{2}\left(\mathrm{Th}_{2} \mathrm{Ni}_{17}\right.$ type hexagonal), $\alpha \mathrm{Fe}_{17} \mathrm{Gd}_{2} \quad\left(\mathrm{Th}_{2} \mathrm{Zn}_{17}\right.$-type rhombohedral), $\quad \mathrm{Fe}_{23} \mathrm{Gd}_{6} \quad\left(D 8_{a}, \quad \mathrm{Mn}_{23} \mathrm{Th}_{6}\right.$-type cubic $), \quad \mathrm{Fe}_{3} \mathrm{Gd}$ $\left(\mathrm{Ni}_{3} \mathrm{Pu}\right.$-type rhombohedral), and $\mathrm{Fe}_{2} \mathrm{Gd}\left(\mathrm{C} 15, \mathrm{MgCu}_{2^{-}}\right.$ type cubic). The $\mathrm{Fe}-\mathrm{Sb}$ phase diagram [Massalski2] has two intermediate phases: $\mathrm{FeSb}_{1-x}\left(B 8_{1}\right.$, NiAs-type hexagonal) and $\mathrm{FeSb}_{2}$ (orthorhombic). The Gd-Sb phase diagram [Massalski2, 2008Liu] has the following intermediate phases: $\mathrm{Gd}_{5} \mathrm{Sb}_{3}\left(D 8_{8}, \mathrm{Mn}_{5} \mathrm{Si}_{3}\right.$-type hexagonal $)$, $\mathrm{Gd}_{4} \mathrm{Sb}_{3}\left(D 7_{3}, \mathrm{Th}_{3} \mathrm{P}_{4}\right.$-type cubic), $\beta \mathrm{GdSb}, \alpha \mathrm{GdSb}(B 1$, $\mathrm{NaCl}$-type cubic), and $\mathrm{Gd}_{16} \mathrm{Sb}_{39}\left(\mathrm{Gd}_{16} \mathrm{Sb}_{39}\right.$-type monoclinic).

\section{Ternary Compound}

[1994Lei] identified a ternary compound at the composition $\mathrm{GdFe}_{1-x} \mathrm{Sb}_{2}$ in arc-melted samples annealed at $800{ }^{\circ} \mathrm{C}$ for 7 days. It has the $\mathrm{ZrCuSi}_{2}$-type tetragonal structure (space group $P 4 / \mathrm{nmm}$ ).

\section{Ternary Isothermal Section}

With starting metals of $99.9 \% \mathrm{Fe}, 99.9 \% \mathrm{Gd}$ and $99.99 \%$ $\mathrm{Sb}$, [2008Liu] arc-melted 147 alloys under Ar atm. The final anneal was at $500{ }^{\circ} \mathrm{C}$ for 7 days, followed by quenching in liquid nitrogen. The phase equilibria were studied mainly by $\mathrm{x}$-ray powder diffraction. The isothermal section constructed by [2008Liu] at $500{ }^{\circ} \mathrm{C}$ is redrawn in Fig. 1 . The binary compound $\mathrm{Fe}_{23} \mathrm{Gd}_{6}$ was not found by [2008Liu] at this temperature. The conflicting results in the literature regarding the temperature range of stability of this compound were

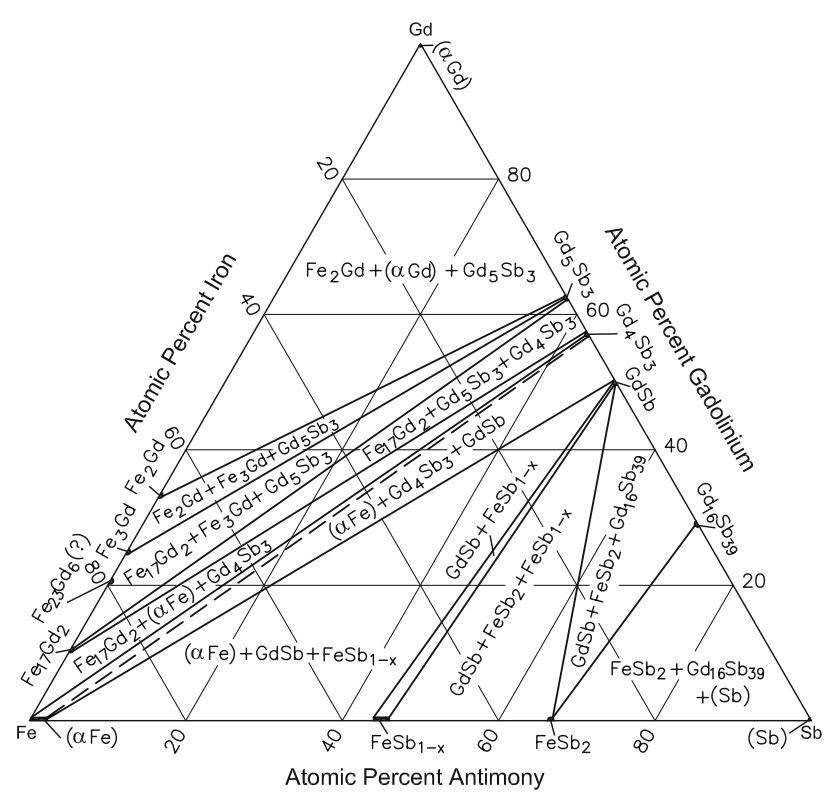

Fig. 1 Fe-Gd-Sb isothermal section at $500{ }^{\circ} \mathrm{C}$ [2008Liu]. Narrow two-phase regions are omitted

discussed by [1998Zha], who, however, concluded that the phase is stable down to room temperature. The third component solubility in the binary compounds is negligible [2008Liu]. The ternary phase $\mathrm{GdFe}_{1-x} \mathrm{Sb}_{2}$ found at $800{ }^{\circ} \mathrm{C}$ by [1994Lei] was not found by [2008Liu] at $500{ }^{\circ} \mathrm{C}$.

\section{References}

1994Lei: A. Leithe-Jasper and P. Rogl, The Crystal Structure of $\mathrm{NdFe}_{1-x} \mathrm{Sb}_{2}$ and Isotypic Compounds $\mathrm{RE}(\mathrm{Fe}, \mathrm{Co})_{1-x} \mathrm{Sb}_{2}$ (RE = La, Ce, Pr, Sm, Gd), J. Alloys Compd., 1994, 203, p 133-136

1998Zha: W. Zhang, C. Li, X. Su, and K. Han, An Updated Evaluation of the Fe-Gd (Iron-Gadolinium) System, J. Phase Equilib., 1998, 19(1), p 56-63

2008Liu: J. Liu, X. Cui, X. Wang, B. Zong, K. Su, X. Yang, and J. Li, Phase Relationships in the Gd-Fe-Sb System at $773 \mathrm{~K}$, J. Alloys Compd., 2008, 465, p 61-63 